\title{
Per Hour
}

National Cancer Institute

\section{Source}

National Cancer Institute. Per Hour. NCI Thesaurus. Code C66966.

A frequency rate of occurrences of something within a period of time equal to sixty minutes. 